\title{
Parques ambientais urbanos de Teresina, Piauí: ambiente, conservação e uso pela população local
}

\author{
Albert Isaac GomesViana ${ }^{(a)}$,Iracilde Maria de Moura Fé Lima ${ }^{(b)}$ \\ (a) Mestrando do Programa de Pós-graduação em Geografia/UFPI. E-mail: xaigvx @ gmail.com

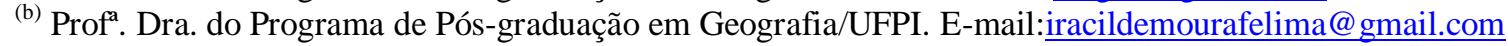

\section{EIXO: BIOGEOGRAFIA, MANEJO DE ÁREAS NATURAIS E PROTEGIDAS: CONSERVAÇÃO DA BIODIVERSIDADE}

\begin{abstract}
Resumo
O presente trabalho buscou traçar um perfil de dois parques da cidade de Teresina-PI: o Parque da Cidade e o Parque Potycabana, abordando aspectos do ambiente, de sua conservação e uso pela população local. A escolha desses Parque deveu-se à sua localização nas margens do rio Poti, em bairros bem servidos de infraestrutura urbana ecom facilidade de acesso.A metodologia adotada envolveu leitura e análise de referenciais teóricos e sobre as áreas estudadas, complementadas com observações em campo, utilizando instrumentos como GPS e câmera fotográfica. Para espacializar esses Parques, trabalhou-se os dados coletadosutilizando-se os softwaresArcGis, QGis e o GoogleEarth. Os resultados permitiramidentificar-se que,embora ambos estejam localizados nas margens do mesmo rio em locais de fácil acesso, esses Parquesse apresentam com características bem distintasem relação ao ambiente natural, sua conservação e formas de uso pela população local.
\end{abstract}

Palavras-chave: Parque Ambiental;Rio Poti;Conservação ambiental; Uso público; Qualidade de vida.

\section{Introdução}

O contínuo crescimento populacional e expansão do sítio urbanode Teresina vem provocando o surgimento de expressivos casos de problemas ambientais, oriundos da falta de planejamento de áreas verdes públicas, bem como de campanhas voltadas para a conservação e uso adequado dos parques e praças existentes. Tendo em vista que somente a partir da segunda metade do século XX as discussões a respeito dos problemas ambientais associados aos modelos de desenvolvimento econômico, que teve como um dos momentos relevantes a Eco-92, realizada no Rio de Janeiro, as preocupações com este tema tornaram-se mais intensas. Sobre essa questão, Loboda e Angelis (2002) salientam que a implantação de áreas verdes no espaço urbano tornou-se, a partir de então, ícone de defesa do meio ambiente.

Ratifica-se ainda que os parques ambientais urbanos geralmente desempenham um papel vital para o bem-estar social e a conservação da natureza. Quanto aos benefícios sociais, pode-se dizer que esses espaços promovem uma fuga da vida cotidiana conturbada das grandes cidades, que por sua vez contribuem com o bem-estar físico e mental das pessoas. Com relação aos aspectos ambientais, essas áreas contribuem de diversas maneiras, dentre elas destacam-se a preservação de espécies de plantas e animais, a melhoria do microclima (e do conforto térmico) e da qualidade do ar, além de benefícios 
OS DESAFIOS DA GEOGRAFIA FÍSICA NA FRONTEIRA DO CONHECIMENTO

Instituto de Geociências - Unicamp

Campinas - SP

28 de Junho à 02 de Julho de 2017

quanto ao aumento da infiltração da água no solo reduzindo,dentro outros, os problemas causados pelas enchentes (TUCCI; COLLISCHONN, 1998).

Assim, para efeito da legislação, o Conselho Nacional de Meio Ambienteestabelece:

$\S 1^{\circ}$ Considera-se área verde de domíniopúblico, para efeito desta Resolução, o espaço de domínio público que desempenhe função ecológica, paisagística e recreativa, propiciando a melhoria da qualidade estética, funcional e ambiental da cidade, sendo dotado de vegetação e espaços livres de impermeabilização (Resolução CONAMA n 369/2006, seção III).

Buscando discutir este tema, o objetivo deste trabalho foi traçar um perfil do ambiente de dois parques urbanos de Teresina-PI: o Parque da Cidade e o Parque Potycabana, abordando aspectos do ambiente, de sua conservação e de uso pela população local.

\section{Procedimentos Metodológicos}

Para atingir os objetivos propostos, o trabalho se utilizou dos seguintes procedimentos metodológicos:inicialmente foi realizado o levantamento de informações, através de busca em teses, dissertações, artigos e sítios de internet, sobre os temas discutidos no artigo, bem como estudos sobre os parquesPotycabana e Parque da Cidade. Para nortear a pesquisa em seus aspectos teóricometodológicos e realizar verificação in loco, sustentado no método de observação expedita, seguiu-se principalmente as proposições de Pavezzi Neto e Silva (2012) e de Moraes et al (2016).

A pesquisa também contou com o processamento de dados adquiridos via satélites para a elaboração dos mapas das áreas em estudo. Esse processamento se deu através do softwareQgis versão 2.14, sendo as imagens obtidas de um banco de dados (shapefiles) disponível em sítios de internet das seguintes fontes: Instituto Brasileiro de Geografia e Estatística (IBGE), Instituto Nacional de Pesquisas Espaciais (INPE), Serviço Geológico Brasileiro (CPRM). Também foram utilizadas imagens obtidas através do programa Google Earth Pro, bem como utilização de máquina fotográfica Canon sx530HS para registro das observações de campo.

Salienta-se que a escolha desses parques teve base em dois parâmetros: localização geográfica e a sua administração tendo em vista que, o Parque da Cidade se situa na margem esquerda do rio Poti, na zona Norte da cidade e é administrado pelo poder público municipal de Teresina e oParque Potycabanase encontra na margem direita deste mesmo rio, na zona Leste da cidade e tem sua administração em nível estadual.

Assim, a discussão dos dados e observações locais será desenvolvida buscando-se traçar um perfil dos Parques Potycabana e Parque da Cidade, identificando suas semelhanças e diferenças, em relação a localização em relação ao relevo e ao rio Poti, características ambientais e sua conservação, bem como as formas de uso pela população local, haja vista ambos possuírem características próprias, mesmo 
estando nas margens urbanizadas do mesmo rio.

\section{Referencial Teórico}

O crescimento acelerado e desordenado, bem como o aumento dos fluxos de uma cidade, traz consigo consequências que afetam o ambiente natural, desde as formas de relevo, os solos, a circulação e qualidade das aguas, cobertura vegetal e a vida silvestre de um determinado espaço, como também a própria população local. Assim, a falta de planejamento e de gestão e a vida "corrida" nas cidades são exemplos de problemas que poderão em um determinado momento, desencadear transtornos, sejam eles de caráter social ou ambiental. Com relação ao aspecto ambiental, destacam-se principalmente a perda da biodiversidade da área, afugentamento de espécies e problemas de saúde (MUSSATO, SILVA e SCACABAROSSI, 2001; COSTA, 2003; MOTA, 2003), além da melhoria do microclima, com relação ao conforto térmico e a qualidade do ar, além de benefícios quanto ao aumento da infiltração da água no solo reduzindo, dentro outros, os problemas causados pelas enchentes urbanas (TUCCI; COLLISCHONN, 1998).

$\mathrm{Na}$ busca de meios para minimizar os efeitos negativos decorrentes da grande expansão e da vida agitada dos centros populacionais, a sociedade viu nos parques ambientais urbanos uma maneira de proporcionar melhores condições de vida, pois, além da manutenção do próprio ambiente, os mesmos desempenham uma importante função na preservação de espécies de animais e plantas, caracterizando-se ainda como áreas de lazer. Segundo Zanin (2002, p. 3) "o parque urbano contempla funções ecológicas, estéticas, de lazer e de educação", corroborando o que dita a Sociedade Brasileira de Arborização Urbana (SBAU), por meio da publicação de Sanchotene (2004), para a qual um parque ambiental é uma área verde com dimensões entre $100 \mathrm{~m}^{2} \mathrm{e} 10$ hectares, destinado ao lazer ativo ou passivo, à preservação da flora ou da fauna ou de outros atributos naturais. Considerando que proporciona melhorias para a vida humana,

[...] os Parques Verdes Urbanos (PVU) passam a ser uma realidade que deve estar presente no espaço citadino. Os PVU podem ser caracterizados como espaços de presença abundante de vegetação, nativa ou parcialmente plantada, que cumprem um importante papel tanto para a saúde integral das pessoas, quanto para o equilíbrio do ecossistema (SOUSA, 2015, p. 302).

Assim, os parques ambientais, além de proporcionarem essas melhorias na qualidade de vida e de preservação da biodiversidade, também favorecem o processo de drenagem de águas pluviais e de influência sobre os corpos hídricos (ribeirões e rios, por exemplo). Isso porque a permeabilidade do solo e a vegetação contribuem para a infiltração e escoamento das águas superficiais, impedindo que a mesma venha a provocar grandes inundações nos centros urbanos. Também porquegrande parte dos solos das cidades encontra-se recoberto por asfaltos ou concretos, tornando o escoamento superficial intenso, pois quase toda a água escorre pelas ruas. Considerando que se o sistema de drenagem da 
cidade não funcionar adequadamente, ocorrem problemas como inundações queprovocam danos socioambientais principalmente em áreas com relevo mais baixo expondo a população a riscos socioambientais urbanas (ROMANI, 2011).

A cidade de Teresina conta com mais de 30 Parques Ambientais distribuídos em toda sua malha urbana, segundo dados deTERESINA (2013), dentre os quais destacam-seoito que se apresentam com maior área, variando de 136 a 0,5 hectares, como o Jardim Botânico de Teresina, Parque Ambiental Encontro dos Rios, Parque Lagoas do Norte, Parque Floresta Fóssil, Parque Zoobotânico, Parque Ambiental Caneleiro Sudeste, como também o Parque da Cidade e oPotycabana, sendo os dois últimos o objeto do presente estudo.

Apesar de ter se iniciado um processo de recuperação/revitalização de alguns parques ambientais de Teresina, sinais de degradação desses espaços ainda é recorrente, já que as medidas tomadas são insuficientes para inibirem ou minimizarem seusdesgastes. Em relação a esta questão, destaca-se a situação do Parque Floresta Fóssil, localizadonas duas margens do rio Poti, mesmorepresentando um importante patrimônio geológico e paleontológico, como chamam a atenção Oliveira et al (2014) e Vasconcelos et al (2016). Sobre a situação de conservaçãoe uso deste Parque as pesquisas demonstram que

no local não existe infraestrutura relativa à segurança pública e de apoio aos visitantes, sendo que a frequência se dá ora por alguns pescadores, ora por pessoas que residem no entorno do Parque. Outras evidências são o mau uso do local, com vestígios de fogueiras, vegetação nativa degradada, esgotos não tratados e lixo espalhado por toda área (VASCONCELOS, 2016, p. 241).

Como ferramenta importante em estudos ambientais, Câmara e Davis (2001) relatam que o geoprocessamento permite a realização de diversas análises e integração de dados, assim como a criação de banco de dados georreferenciados, tornando possível a automatização da produção de mapas e outros produtos cartográficos.

\section{Caracterização da Área de Estudo}

O município de Teresina localiza-se no estado do Piauí, com coordenadas do centroide equivalentes

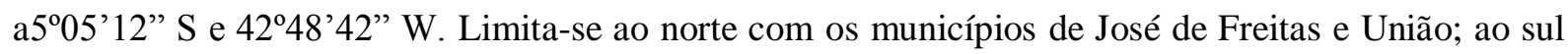
com Monsenhor Gil, Nazária, Palmeirais, Demerval Lobão e Curralinhos; a leste com Lagoa do Piauí, Altos e Pau d'Arco do Piauí e a oeste com o município de Timon (Maranhão) (IBGE, 2010). (Figura 1).Apresenta uma área territorial aproximada de $1.679,8 \mathrm{~km}^{2}$ e com um contingente populacional de 814.230 habitantes, dos quais 767.557 vivem na área urbana, segundo dados do IBGE (2010), e uma estimativa de que em 2016 a população do município seja em torno de 847.430 habitantes (IBGE, 2016). 


\section{OS DESAFIOS DA GEOGRAFIA FÍSICA NA FRONTEIRA DO CONHECIMENTO Instituto de Geociências - Unicamp \\ Campinas - SP \\ 28 de Junho à 02 de Julho de 2017}

O bairro Primavera (SEMPLAN, 2016) possuía no ano de 2010 uma população residente de aproximadamente 9.000 habitantes, uma área total de 141 hectares $\left(1,41 \mathrm{~km}^{2}\right)$ e densidade demográfica de 64,5 hab./hectares, tendo como espaços culturais o Parque da Cidade e o Parque Poti I.O birro Noivos apresentava no ano de 2010 uma população próxima a 4.000 residente, distribuída em uma área de 142 hectares $\left(1,42 \mathrm{~km}^{2}\right)$, com uma densidade demográfica de 38,7 hab./hectare. Ainda segundo essa mesma fonte o bairro noivos possui como espaços culturais o Parque Potycabanae oParque Floresta Fóssil que é destinado a preservação ambiental.

O clima da cidade de Teresina, segundo a classificação de Köppen, caracteriza-se por ser do tipo tropical subúmido quente (Aw'), com o regime de chuvas iniciando a partir da segunda quinzena de dezembro e prolongando-se até o mês de maio, sendo os meses entre fevereiro e abril os mais chuvosos (SILVAet al, 2015). Em relação à vegetação o município de Teresina encontra-se numa faixa de contato das formações vegetais dos tipos floresta subcaducifólia, cerrado e caatingatendo em vista sua posição de contato entre esses biomas (LIMA, 2002).

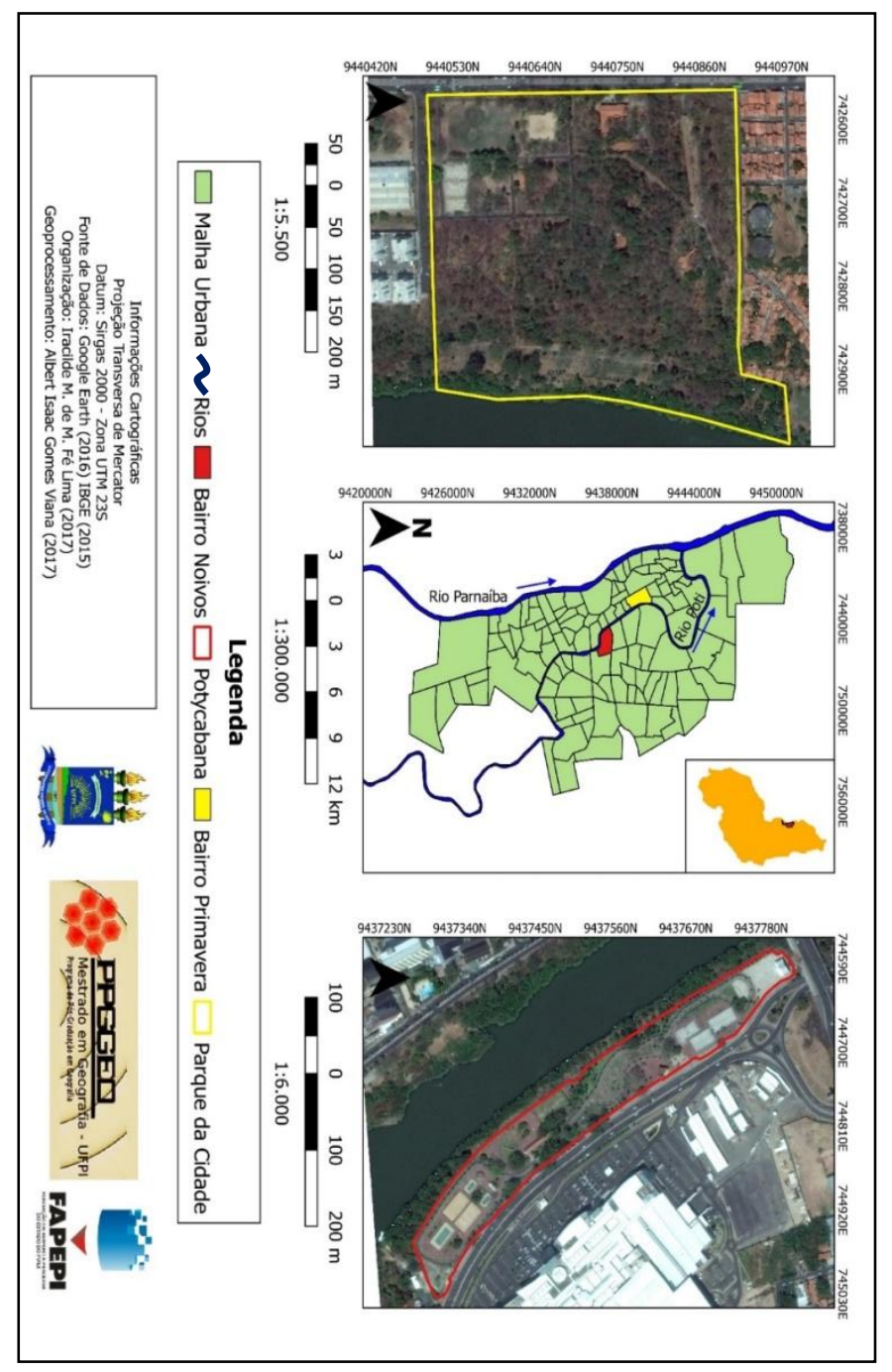

Figura 1 - Mapa da localização e delimitação da área de estudo. 


\section{OS DESAFIOS DA GEOGRAFIA FÍSICA NA FRONTEIRA DO CONHECIMENTO \\ Instituto de Geociências - Unicamp \\ Campinas - SP \\ 28 de Junho à 02 de Julho de 2017}

\section{Resultados e Discussões}

\subsection{Parque da Cidade}

O Parque da Cidade está localizado na Avenida Duque de Caxias, 2960, bairro Primavera II, zona Norte da cidade, inaugurado no ano de 1982. Corresponde a umaunidade de preservação ambiental que apresentauma área de aproximadamente 17 hectares de extensão. "Constitui-se, atualmente, um local para a realização de eventos culturais/ecológicos e de atividades de educação ambiental com escolas e grupos comunitários" (SOBREIRA et al, 2015, p. 1),além de contar com espaços para atividades esportivas, como trilhas para caminhada e campo de futebol, como se observou em trabalhos de campo.

A sua cobertura vegetal apresenta-se predominantemente formada por espécies nativas, sendo mais de 120 espécies vegetais (TERESINA, 2015), apresentando uma vegetação tipicamente arbórea, sendo que, segundo Lima (1996), dentre as espécies de maior frequência estão o pau d'arco(Tabebuia)angico (Anadenanthera colubrina), babaçu (Attaleassp), caneleiro (CenostigmamacrophyllumTul), jatobá (Hymenaeacourbaril), cajá (Spondiasmombin) e sapucaia (Lecythispisonis), árvores que são frequentemente encontradas na vegetação nativa da região (figura 2). Por ter sua vegetação relativamente bem conservadaeste Parque proporciona conforto térmico aos visitantes, tendo em vista as elevadas temperaturasque incidem em Teresina, principalmenteentre os meses de setembro a dezembro, geralmente acima de $30^{\circ} \mathrm{C}$ (INMET, 2016).

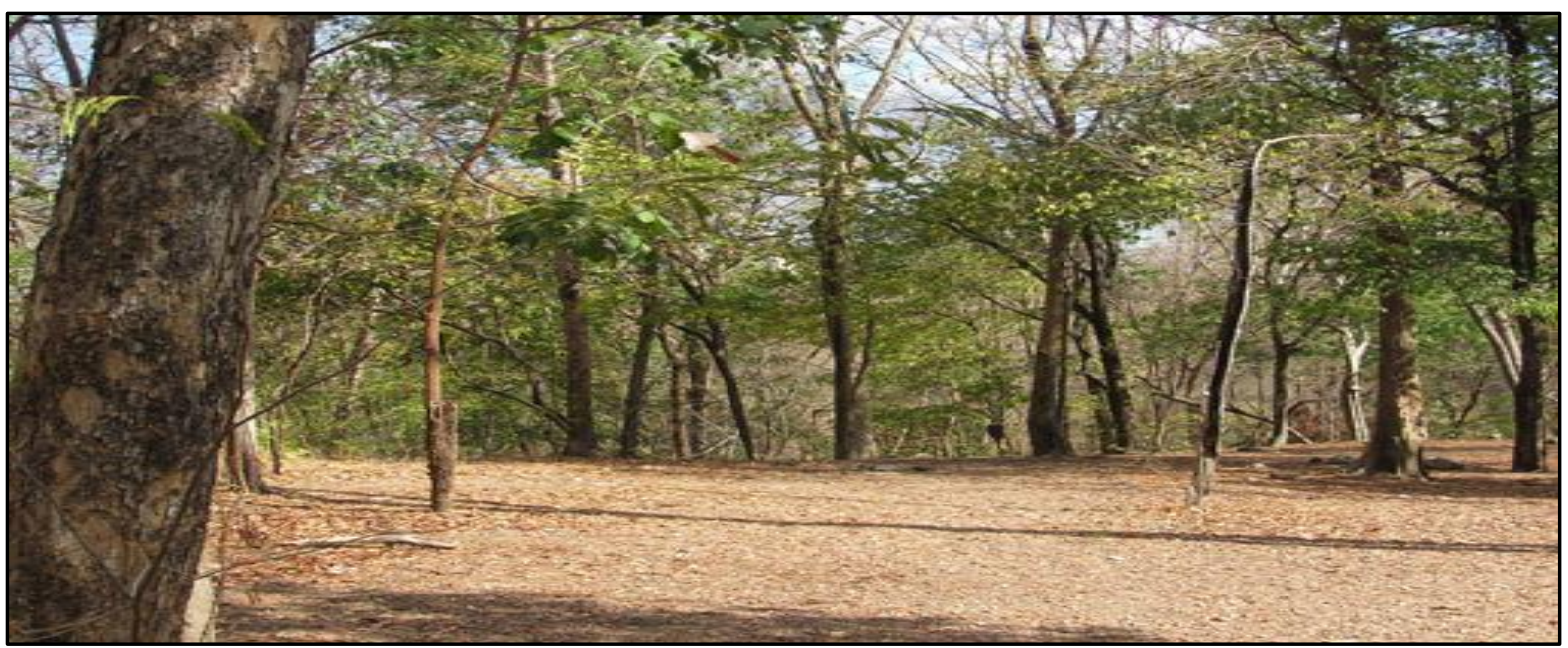

Figura 2 - Fotografia mostrando parte de uma trilha e da vegetação no interior do Parque da Cidade.

Em relação aos aspectos geológicos, o Parque encontra-se em relevo de colinas, onde o ponto mais elevado do parque apresenta áreas de aproximadamente 100 metros de altitude e em parte do terraço fluvial da margem esquerda do rio Poti (Figura 3).As áreas mais elevadas são moldadas na formação Pedra de Fogo, do período Permiano, constituídas de rochas predominantemente areníticas, da Bacia Sedimentar do Parnaíba, enquanto os terraços são formados por depósitos fluviais que se encontram 


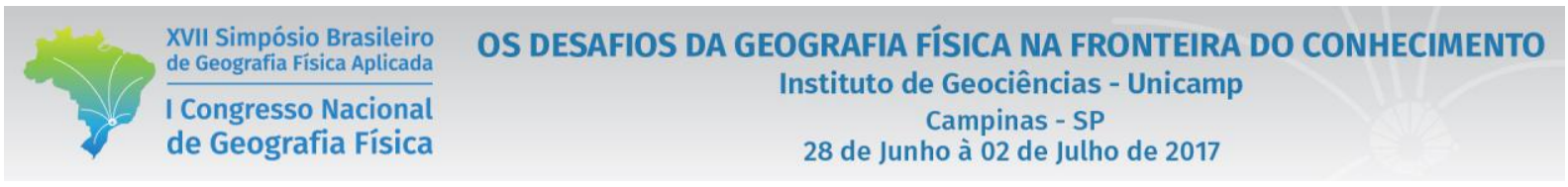

sobre a formação Piauí, sotoposta à Pedra de Fogo, datada do Carbonífero (LIMA, 2013). Esse Parque encontra-se no trecho do baixo curso dabacia do rio Poti, tendo se observado apenas a formação de dois pequenos riachos efêmeros voltados para leste, ou seja, para o rio Poti, onde asencostas apresentam declividades mais acentuadas,porém se descaracterizando nas proximidades do terraço fluvial. Nas áreas onde foi retirada a cobertura vegetal, principalmente nas trilhas e onde existe uma pequena área com playground,como também na área desmatada do terraço observou-se a presença de

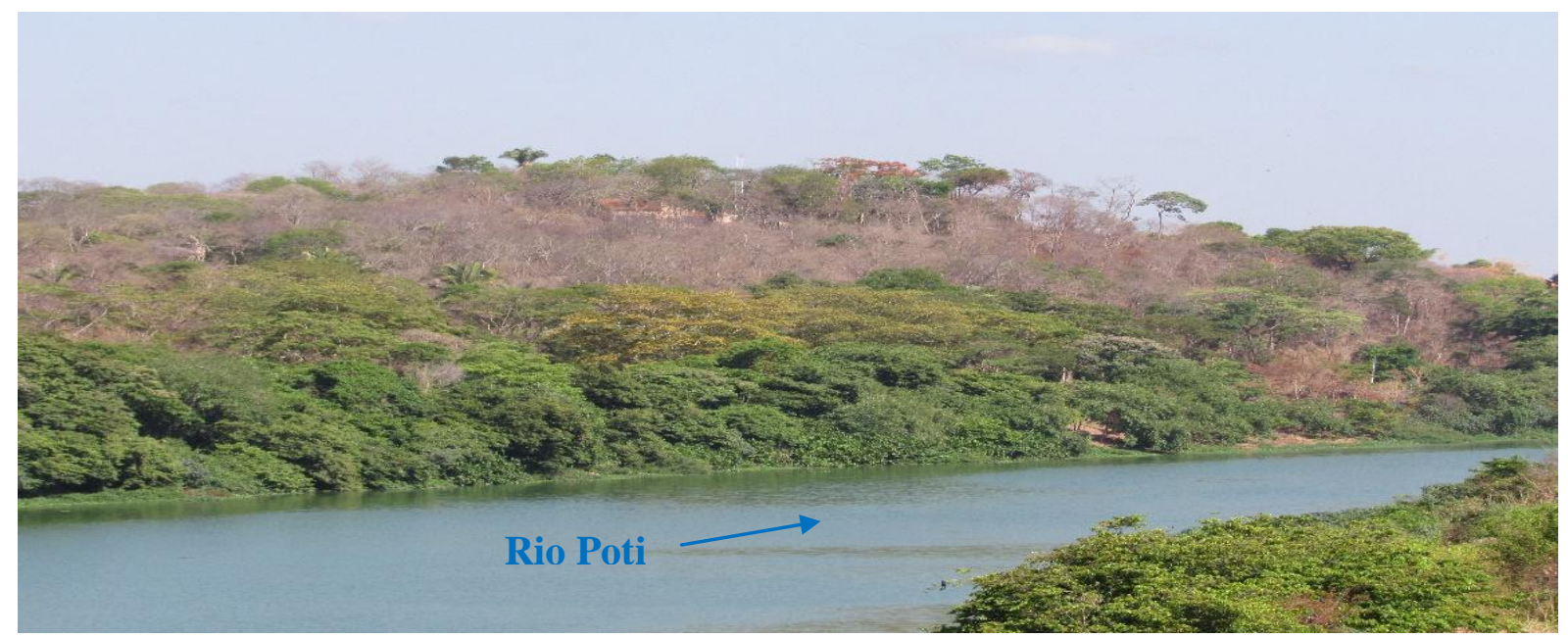

erosão laminar.

Figura 3 - Fotografia de uma visão geral do Parque da Cidade, destacando o relevo de colinas e a cobertura vegetal conservada na margem esquerda do rio Poti.

Observou-se uma grande faixa de área desmatada nesse terraço fluvial onde são realizados pequenos cultivos de hortaliçaspelos moradores das proximidades. Estesplantios são estimulados pelo poder público municipal, como forma de apoio à população de baixa renda, mas por não serem adotadas práticas conservacionistas, contribuem para a instalação de processos de erosão laminar, com o destino dos sedimentos diretamente no rio Poti, representada por setas vermelhas na Figura 4. Destaque-se que, além de se localizarem em Áreas de Proteção Permanente (APP) conforme o Código Florestal de 2012 (Lei n. 12.651/2012), é um tipo de uso conflitante com uma área de conservação ambiental, onde se encontra.

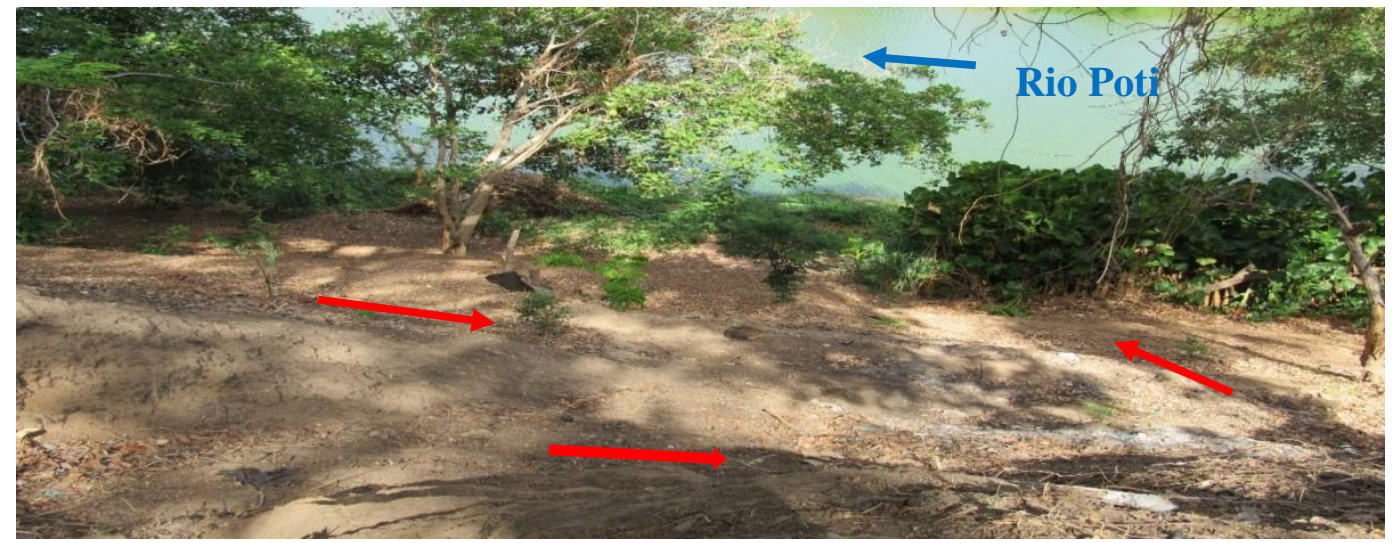

Figura 4 - Presença de processos erosivos no terraço do rio Poti 
XVII Simpósio Brasileiro

de Geografia Fisica Aplicada

I Congresso Nacional

de Geografia Física

\section{OS DESAFIOS DA GEOGRAFIA FÍSICA NA FRONTEIRA DO CONHECIMENTO \\ Instituto de Geociências - Unicamp \\ Campinas - SP \\ 28 de Junho à 02 de Julho de 2017}

Por ser uma área de visitação livre, o Parque está sujeito a sofrer depredações principalmente por não ter um acompanhamento adequado de profissionais que conheçam a área. Além disso, pôde-se observar o abandono parcial por parte da Administraçãopois em nenhum momento da visita foi percebida quaisquer atividades que promovessem o interesse da população em frequentá-lo. Também não dispõe de guias ou outro tipo de orientação para essas visitas, seja de cunho pedagógico-escolar ou turístico/lazer, nem mesmo algum tipo de registro e controle de visitantes, apesar de ter no seu interior instalações de polícia ambiental, de escolas de escoteiros, deeducação ambiental, além da sede administrativa da Secretaria de Meio Ambiente Municipal.

\subsection{Parque Ambiental Potycabana}

O Parque Ambiental Potycabana está localizado na Av. Raul Lopes, no Bairro Noivos, na zona leste da cidade. O início do projeto de construção data do final da década de 1980, sendo efetivamente construído no ano de 1990. Contava inicialmente com uma área de aproximadamente 9 ha, mas após o processo de revitalização finalizado em 2013 a área desse Parque foi reduzida para aproximadamente de 4,3 ha (SARAIVA, 2011).

Com relação à cobertura vegetal,ao contrário do Parque da cidade, observou-se que corresponde predominantemente à vegetação plantada (figura 5), composta em sua maioria por palmeiras e de espécies de adorno (LIMA, 1996). Ainda segundo essa autora, esse Parque representa uma área voltada para o lazer, com pistas de skate, palcos para shows, bares e restaurantes, além de recentemente contar também com quadras de esporte e pistas para prática de ciclismo e cooper, uma vez que o Parque surgiu com o objetivo de promover um espaço recreativo para a população.

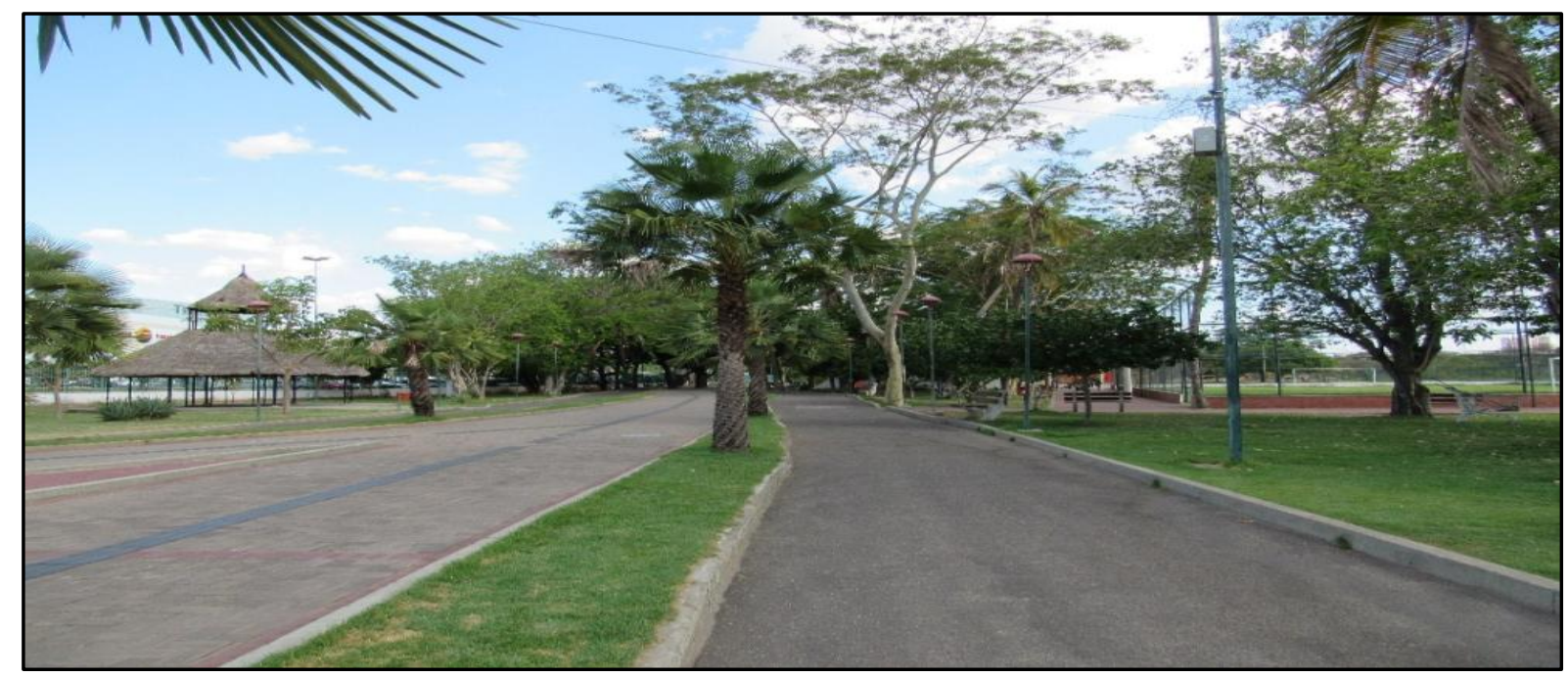

Figura 5 - Fotografia mostrando a cobertura vegetal, áreas impermeabilizadas e equipamentos de apoio ao lazer no interior do Parque Potycabana.

Em relação ao relevo da área desse Parque, Lima (2011) destaca que se encontra totalmente no terraço da margem direita do rio Poti, portanto, composta por sedimentos aluviais, também em área de 


\section{OS DESAFIOS DA GEOGRAFIA FÍSICA NA FRONTEIRA DO CONHECIMENTO \\ Instituto de Geociências - Unicamp \\ Campinas - SP \\ 28 de Junho à 02 de Julho de 2017}

APP.Assim, apresenta-se em terreno praticamente plano, onde se encontra embutido o leito do rio, com declividades de até $3 \%$.

A cobertura dos solos é composta em grande parte por asfalto e blocos de concreto (Figura 6A), o que contribui para reduzi a infiltração da água das chuvas no solo. Percebeu-se também durante asobservações in locoqueforam realizados trabalhos de contenção de processos erosivo (indicados por setas vermelhas na Figura 6B), e consequente assoreamento, através de técnicas de proteção dos taludes buscando, evitar quedas de margens durante a elevação do nível do rio em períodos de cheias excepcionais.
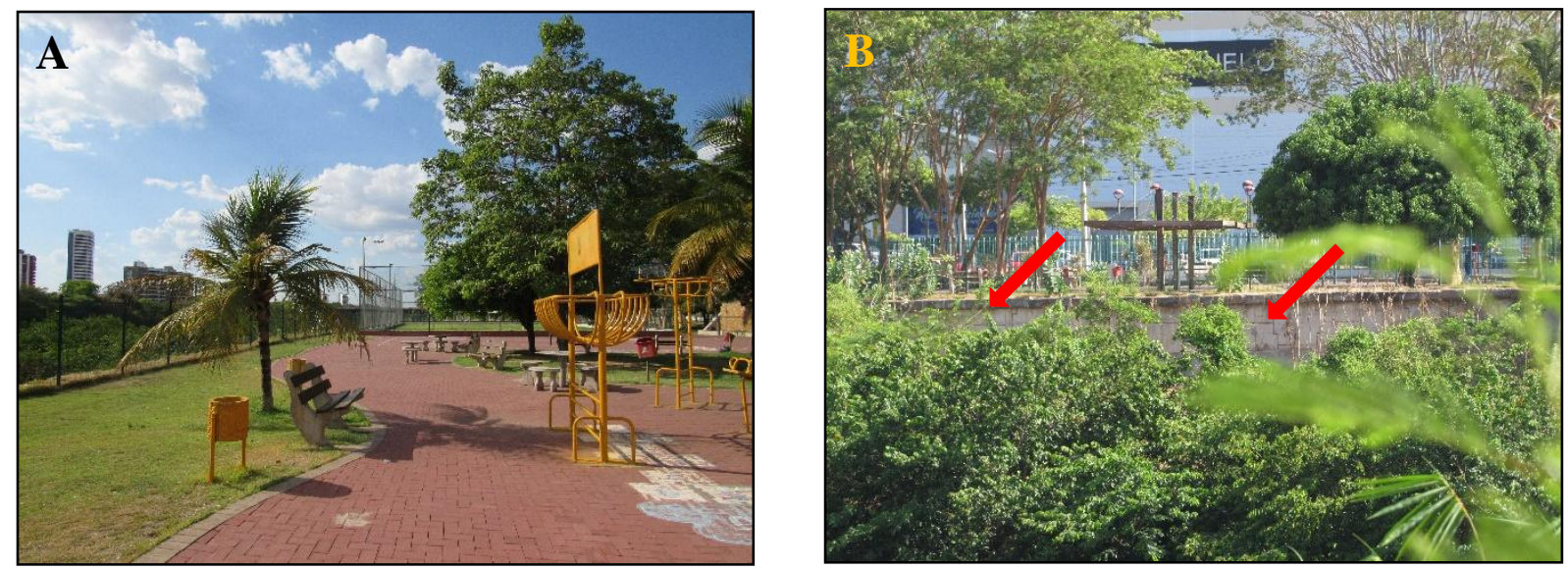

Figura 6 - Fotografia mostrando grandes áreas impermeabilizadas do Parque Potycabana (A) e um dique de contenção dos processos erosivos (B).

Em relação às políticas de incentivo à visitação do parque, são realizados eventos e promoção de atividades de lazer com maior regularidade do que no Parque da Cidade para motivar o seu uso pela população,principalmente após a reforma do Parque. Destaque-se que esta proporcionou melhorias significativas para a estrutura do mesmo, passando a ser conhecido como Parque "Nova"Potycabana.

\section{Conclusão}

Os resultados permitiram concluir que esses dois Parques apresentam diferenças significativas em relação ao ambiente e ao seu uso, mesmo estando ambos ocupando as margens do mesmo rio na área urbana. As diferenciações de características observadasforam,principalmente, em relação ao relevo e à cobertura vegetal, além da presença de equipamentos e promoções de atividades de lazer e, portanto, do seu uso pela população.

Desta forma,considerou-se que a própria destinação de cada um dos Parques corresponde aofator que promove essas diferenças, pois o Parque da Cidade se caracteriza por ter uma destinação voltada, predominantemente, para a conservação do ambiente natural. Já o Parque Potycabana se destina à promoção do lazer à população. Desta forma, este apresenta um grau de visitação elevado, se comparado com o Parque da Cidade, uma vez que não existem estímulos à visitação para fins 
educativos ou de contemplação da natureza.

Tendo em vista a importância dos Parques Ambientais para Teresina, seria importante chamar a atenção dos seus administradores estaduais e municipais, para o fato de que um investimento em sua conservação, bem como a promoção e orientação de atividades educativas associadas ao lazer certamente contribuirão para elevar a qualidade do ambiente urbano e o bem estar da sua população.

\section{Agradecimentos}

Quero agradecer a Fundação de Amparo à Pesquisa do Estado do Piauí - FAPEPI, ao Programa de Pós-Graduação em Geografia - PPGGEO/UFPI por proporcionar meios para a elaboração deste trabalho, que para mim desempenhou uma importante contribuição para minha pesquisa de mestrado, possibilitando o aprimoramento de minhas atividades.Agradeço também ao nosso Grupo de Pesquisa:Geomorfologia, Analise Ambiental e Educação da qual faço parte.

\section{Bibliografia}

CÂMARA, G.; DAVIS, C. Geoprocessamento - Teoria e Aplicações. São José Dos Campos: Instituto Nacional de Pesquisas Espaciais, 2001.

CONAMA. Conselho Nacional do Meio Ambiente. Resolução n ${ }^{\circ}$ 369, de 28 de março de 2006. Diário Oficial da União, Edição Número 61, de 29/03/2006. Disponível em: <http://www.mma.gov.br/port/conama/legiabre.cfm?codlegi=489>. Acesso em: 23 jun. 2016.

COSTA, A. A.Crescimento urbano e problemas socioespaciais: um estudo da periferia de Natal. Mercator Revista de Geografia da UFC, ano 02, número 04, 2003.

EMBRAPA. EMPRESA BRASILEIRA DE PESQUISA AGROPECUÁRIA. Mapa ExploratórioReconhecimento de solos do Município de Teresina, PI. 1983. Disponível em: <http://www.uep.cnps.embrapa.br/solos/index.php?link=pi>. Acesso em: 10. nov. 2016.

INMET. INSTITUTO NACIONAL DE METEOROLOGIA - INMET- Dados meteorológicos. Disponível em: <http://www.inmet.gov.br/> acesso dia 6 dez de 2016.

LIMA, I. M. M. F. O relevo de Teresina, PI: compartimentação e dinâmica atual. In: ENCONTRO NACIONAL DA ASSOCIAÇÃO NACIONAL DE PÓS-GRADUAÇÃO E PESQUISA EM GEOGRAFIA, 9., Goiânia, 2011. Anais... Goiânia, 2011.Disponível em: 〈http://iracildefelima.webnode.com〉. Acesso em: 10 nov. 2016.

Teresina - Agenda 21. Meio Ambiente (Coord.). In: Plano de Desenvolvimento Sustentável. Secretaria Municipal de Planejamento e Coordenação Geral. Teresina: PMT, 2002.

Revalorizando o verde em Teresina: o papel das unidades ambientais. In: Cadernos de Teresina. Teresina: Fundação Mons. Chaves. Ano X, n 24, dez. 1996.

IBGE - INSTITUTO BRASILEIRO DE GEOGRAFIA E ESTATÍ́STICA. Censo demográfico 2010. Rio de Janeiro, 2010.

LOBODA, C. A.; ANGELIS, B. L. D. Áreas verdes públicas urbanas: conceitos, usos e funções. Ambiência, Guarapuava, v. 1, n. 1, jan./jun. 2005 . p.p. 125 - 139. Disponível em: $<$ http://revistas.unicentro.br/index.php/ambiencia/article/download/157/185>. Acesso em: 22 nov. 2016.

MORAES, B.C.; CARVALHO, R. C. P. S.; FEITOSA, M. S. S.; ARAÚJO, M. F. V..O Método Expedito como Estratégia de Avaliação Qualitativa dos Níveis de Vulnerabilidade em Ambientes da Zona Urbana de Teresina, Piauí. Revista Equador, v. 05 nº 3, p. 500-517, 2016.

MOTA, S.Urbanização e meio ambiente.3. ed. Rio de Janeiro: ABES, 2003. 352 p. 
OS DESAFIOS DA GEOGRAFIA FÍSICA NA FRONTEIRA DO CONHECIMENTO

Instituto de Geociências - Unicamp

Campinas - SP

28 de Junho à 02 de Julho de 2017

MUSSATO, O. B.; SILVA, G. F. N.; SCACABAROSSI, H. Expansão urbana desordenada como fator de comprometimento do meio ambiente na Amazônia Setentrional: um estudo de caso das condições socioambientais da área denominada bairro Senador Hélio Campos na cidade de Boa Vista-RR. In: ENCONTRO NACIONAL DOS GEÓGRAFOS, 16. Anais. ENCONTRO NACIONAL DOS GEÓGRAFOS, Porto Alegre, 2010

OLIVEIRA, L. N.; FREITAS, J. S.; PINHO, S. P. Contribuição do parque floresta fóssil no meio urbano de Teresina (PI). Revista Equador, v. 3, p. 82-93, 2014.

PAVEZZI-NETTO, M.; SILVA, R.S. Método expedito para análise da qualidade ambiental em zonas ripárias urbanas. Paranoá (UnB), v. 4, p. 61-68, 2012. Disponível em: <http://periodicos.unb.br/index.php/paranoa/article/viewFile/12314/8595>. Acesso em: 22 nov. 2016.

ROMANI, G. N. Análise florística, fitossociológica e qualitativa da arborização na Praça XV de Novembro em Ribeirão Preto, SP. 2011. 61 f. Dissertação (Mestrado) - Universidade Estadual Paulista, Faculdade de Ciências Agrárias e Veterinárias, 2011. Disponível em: 〈http://hdl.handle.net/11449/96887>. Acesso em: 08 nov. 2016

SANCHOTENE, M. C.C. Conceitos e Composição do índice de áreas verdes. Boletim Informativo da Sociedade Brasileira de Arborização Urbana, n.1, p.4-9, 2004.

SARAIVA,S. V.Intervenções arquitetônicas contemporâneas em Teresina: Parque Potycabana. Estudo arquitetônico da obra e sua intervenção na cidade:1990-2010. 2011. Projeto de Iniciação Científica Universidade Federal do Piauí, Conselho Nacional de Desenvolvimento Científico e Tecnológico. 2011. Disponível em: <http://leg.ufpi.br/20sic/Documentos/RESUMOS/Modalidade/Exatas/b710915795b9e9c02cf10d6d2bdb688c.pdf >. Acesso em: 20 nov. 2016.

SILVA, V. M. A.; MEDEIROS, R. M; RIBEIRO, V. H. A. ; SANTOS, E. D. ; FARIAS, M. E. A. C. . Climatologia da precipitação no município de Teresina, PI, Brasil. In: CONGRESSO TÉCNICO CIENTÍFICO DE ENGENHARIA E DA AGRONOMIA, 72. Fortaleza, 2015. Anais.... Fortaleza, 2015. Disponível em: < http://www.confea.org.br/media/Agronomia_climatologia_da_precipitacao_no_municipio_de_teresina_pi_brasil .pdf>. Acesso em: 20 nov. 2016.

SOBREIRA, M. G. A.; FORTES, A. C. C.; DANTAS, F. R.; SANTOS, L. A.; PEREIRA, T. J. S. M...Parque ambiental João Mendes Olímpio de Melo: estrutura, funcionamento e uso como instrumento de educação ambiental na cidade de Teresina, Piaú. 2015. Disponível em: < http://www.ibeas.org.br/congresso/Trabalhos2015/VI-039.pdf>. Acesso em: 15 nov. 2016.

SOUSA, A. L.; MEDEIROS, J. S.; ALBUQUERQUE, D. S.; HIGUCHI, M. I. G. Parque Verde Urbano como Espaço de Desenvolvimento Psicossocial e Sensibilização Socioambiental. Psico (PUCRS. Online), v. 46, p. 301-310, 2015.

TERESINA. Prefeitura Municipal de Teresina/Secretaria Municipal do Desenvolvimento Econômico e Turismo - SEMDEC. Plano de desenvolvimento Integrado do Turismo Sustentável (PDITS). Teresina: PMT, 2011.

Prefeitura Municipal de Teresina/ Secretário Municipal do Meio Ambiente, 1995. Regimento Interno. Teresina: SEMAM/PMT. 2013.

Prefeitura Municipal de Teresina/ Secretário Municipal de Planejamento e Coordenação - SEMPLAN. ÁREAS VERDES. Teresina: SEMPLAN/PMT. 2015.

Prefeitura Municipal de Teresina/ Secretário Municipal de Planejamento e Coordenação - SEMPLAN. Perfil dos Bairros. Teresina: SEMPLAN/PMT. 2015.

TUCCI, C. E. M.; COLLISCHONN, W.Drenagem urbana e controle de erosão. In: SIMPÓSIO NACIONAL DE CONTROLE DA EROSÃO, 6, Presidente Prudente, 1998. Anais... Presidente Prudente, 1998.

VASCONCELOS, M. V. de; LIMA, I. M. M. F. Floresta fóssil do rio Poti em Teresina, Piauí: porque não preservar? In: Revista Equador. v. 5,n 3 . 2016. p. 239 - $259 . \quad$ Disponível em:<http://iracildefelima.webnode.com/sobre-teresina>. Acesso em: $10 \mathrm{dez} 2016$.

ZANIN, E. MCaracterização ambiental de um parque urbano - Parque Municipal Longines Malinowski, Erechim, RS. Edifapes, 2002. Disponível em < http://www.lapa.ufscar.br/livros/caracterizacao-ambiental-de-umparque-urbano-parque-municipallongines-malinowski-erechim-rs>. Acesso em 21 jun. 2016. 